\title{
Wordless Picture Books beyond School Boundaries: Visual Bridges toward Family-School Partnerships in Education ${ }^{\dagger}$
}

\author{
Cinzia Zadra \\ Faculty of Education, Free University of Bolzano-Bozen, 39100 Bolzano, Italy; cinzia.zadra@unibz.it \\ + Presented at the International and interdisciplinary conference IMMAGINI? Image and Imagination \\ between representation, communication, education and psychology, Brixen, Italy, 27-28 November 2017. \\ Published: 17 November 2017
}

\begin{abstract}
This article discusses how the shared reading of wordless picture books can contribute to the promotion of parental educational engagement by fostering shared visual reading practices. Prior research shows that wordless picture books contribute to making the reader feel in the story, and facilitate the process of empathy and participation. The content analysis of data collected during a reading project, which involves shared reading with children and their parents, reveals that child-parent shared reading of a visual narrative establishes intense interaction and collaboration, a deep emotional relationship and promotes and enhances the role of the family in an expanded learning community.
\end{abstract}

Keywords: wordless picture books; shared visual reading; co-construction of meaning; relationship school-family; expanded learning community

\section{Introduction}

Narrators often start from images whether they are mental images or true illustrations to get to words. Italo Calvino argues that "in devising a story, the first thing that comes to my mind is an image that for some reason strikes me as charged with meaning, even if I can not formulate this meaning in discursive or conceptual terms" [1] (p. 88-89).

This article deals with narrative that contains only illustrations and, in particular, with the shared visual reading of wordless children's picture books and presents the results of a data analysis collected by a research project. The research was carried out between 2015 and 2017 in kindergarten and primary schools in Northern Italy and involves children and their families.

In this contribution the wordless picture books have been the subject of an analysis that starts both from literary and educational perspectives. While most recent studies concentrate on a reader's active role and the co-construct of the meaning of picture books through reading, re-reading and image interpretation, the research seeks to explore the opportunities and benefits offered by wordless picture books, with a view to widening the use of picture books in reading projects outside of school, that involve and engage the children's families.

The principal aim of the investigation was to look in depth at how visual literature is read by children and parents together.

The subsidiary aim was to understand how shared reading can help build networks of collaboration between school and family and how it can constitute a context of extended learning that can break the strict boundaries between school, families and social context. This often makes school, with its tasks and its contexts of learning, a concealed and misunderstood place, and school is subject to the criticism of its intrinsic inability to relate to the real and daily life of children by offering the promotion of inert and encapsulated knowledge [2]. 
Sixteen primary schools and twenty kindergartens participated in the research, ranging from multilingual schools in an urban setting to monolingual mountain schools. In each school, one or two children had the opportunity to read an illustrated book at home with a parent. After the shared reading, both parent and child were asked, via a semi-structured qualitative interview, about the reading process and their perception of the shared reading experience. Many of the selected questions came about by crossing the literary and educational perspective, following the suggestions of one of the most prolific researchers of the visual narrative at international level, Evelyn Arizpe, who encourages more interdisciplinary research in relation to the role the reader thinks to take in different contexts when reading wordless picture books, and took into account previous research about wordless picture books [3-7]. In depth, semi-structured interviews were conducted with 90 children and 87 parents. An interview schedule was closely followed with four common questions regarding shared reading, reading procedure and strategies; construction of meaning; negotiation of interpretation and satisfaction grade of experience. This was followed by open comments about the educational and emotional value of shared reading and the wordless picture books. The collected data were analysed via a qualitative content analysis [8].

\section{Theoretical Background}

Wordless picture books have attracted attention and curiosity for many years in various disciplinary areas, especially in relation to interactive quality [6] (p. 99) and the active participation of the reader in the process of the co-construction of meaning and of language.

Sandra Beckett highlighted how the publication of wordless picture books is a "publishing trend" with authors dedicated exclusively to the genre. It also seems significant that more and more wordless picture books have won the Caldecott Award in the last few years [6].

The definition of wordless picture books in academia is often discussed. The same word 'wordless' is ambiguous because in wordless books you can never completely exclude the presence of words that are often used in titles, or within the same images in the form of, for example, insignia or advertising posters or on the back cover. Even different languages mention this type of visual narration in very different ways: wordless picture books, or wordless picturebooks [4] (p. 5); sequenced picture texts [9] (p. 221); álbum sin palabras [10] visually rendered narrative [11] (p. 24) and silent books, the striking English expression commonly used in Italian [12,13]. Wordless or "nearly wordless" picture books consist of images without the accompaniment of words: the narration and meanings of the text are guided solely by the illustrations and they should not be defined "by what they do not contain: words" [11] (p. 24), but by the focus on the visual narrative.

Many visual narratives also belongs to a genre that have as an audience the world of childhood and were welcomed by a largely adult audience and are therefore able to place themselves as a "crossover", somewhere in between children and adults of all ages, breaking down the limits of age and declining as intergenerational works.

There are many studies that investigate the nature, definitions and didactic uses of wordless books. Much recent research has contributed to establishing their intercultural and multidisciplinary value, and to extending the possibilities of analysing the mechanisms underlying them from the point of view of narrative and the semiotic of images [4-14].

Arizpe emphasized the importance of defining picture books for the weight and value that images take in the meaning making process [4]. Shaun Tan, award-winning author of wordless picture books, talking about one of his books, The Arrival, argues that the absence of words contributes to making the reader feel in the story, and making him identify himself with the characters, facilitating processes of empathy and participation. The fact that no word addresses the reader to a precise interpretation of history leaves room for thoughts, and offers "more conceptual space around it, and invite a more lingering attention from a reader who might otherwise reach for the nearest convenient caption, and let that rule their imagination" [15].

After all, Tan says, the images are not so different from the words: each image has a voice that can create different realities in the mind of those looking at it [15] (p. 4). Many researchers, in fact, reveal that narrative illustrations of quality allow for a very free flow of thoughts, an intimate 
reading of images that relativizes the role of comments, prejudices and pre-existing linguistic or cultural constructions [9-11]. Tan affirms that there seems to be some kind of silent recognition from those who deal with graphic novels about the impossibility of using words to express themselves. Words seem to escape the fluid, indefinite, ambivalent and vague character of many ideas, concepts, and emotions. Images are able to liberate and subvert words, and expand their meaning; a wordless story is always a new story, a story never told before, a story that changes and grows and transforms every new reader's gaze. Tan's words echo Calvino in Six memos for the Next Millennium: "[...] it is the images themselves that develop their own implicit potentialities, the story they carry within them" [1] (p. 89) and emphasize the potential of the images that is not only visual but also conceptual.

The reading of a visual narration goes beyond reading a text, in fact "the images open a further world on the facts of the stories told" [16]. The imagination and interpretation of the reader "are more important than those of an author and certainly more important than the style or category of their work" [15] (p. 8). Calvino himself had anticipated that "reading pictures without words was certainly a schooling in fable-making, in stylization, in the composition of the image" [1] (p. 94).

The theoretical background that creates the framework of this research lies on a double matrix. On the one hand, we refer to narrative and textual researches of picture books and, in particular, to picture books consisting only of images and without words, to which the English-speaking world, specially, has devoted important contributions and research [3-6,17]. But most of our questions refer to socio-cultural pedagogical approaches that recognize in the school a system of activities, and stress how the effectiveness of learning is closely related to activities outside the classroom. Learning is intended as an expansion of activities and thus is embedded in a network of relationships with the community outside school that redesigns the school as an open and interactive system and facilitates the transferability of learning in the contexts of everyday life [18].

The research project under investigation addresses the extracurricular community by considering the family as a privileged partner of the educational relationship, enabling the learning process to expand and intertwine in new links of meaning. The project refers to the socio-cultural theories of learning, which, starting from the idea of community of practice in Lave and Wenger [19], considers learning as embedded in interactive practice and in contexts. This model indicates the possibility of structuring school as a research community that produces skills for its members and for the social community of which it is part. The social learning theory is particularly concerned with our project because it defines social participation as a process of learning and knowing. Knowledge is competence for a number of socially appreciated activities; it is participation and it is a meaningful experience. Participating in parent-school activities is at the same time a form of action but also a form of belonging; Participation does not only affect what we do, but also how we interpret what we do and who we are. So, participation in the reading project involves the creation of a small community of practice between people who have a common action marked by a place of exchange and interaction, by a sharing of words and themes, and finally by the awareness of belonging to a common story.

This idea of learning also refers to Engeström's system of activities, which allows you to look at the interaction between the school system and all the other places next to it: the community and the family. Engeström argues that learning occurs in a process of expanding actions and practices that give rise to a new activity [20]. Starting from the idea of school as a system of activity means seeing in the school a plurality of functions. Ajello and Ghione [21] emphasize how the effectiveness of the school community is closely related to activities outside the classroom. That is why building networks and relationships with the extracurricular community and enhancing the different forms of learning, means redesigning the school as an open and interactive system.

\section{Research Design and Methodology}

The picture books chosen for the research are Spring-Wimmelbook of Rotraut Susanne Berner [22] for the kindergarten and The Red Book of Barbara Lehman [23] for the primary school. 
Spring-Wimmelbook was first published in Germany in 2003 with the title Frühling-Wimmelbuch. It is a large book made of cardboard that contains double-pages presents a panoramic sequence of pictures linked by different plot threads [14] (p. 124).

Rotraut Susanne Berner is an important German illustrator who won the Hans Christian Andersen Award for illustration in 2016. The award mentions the Wimmelbooks series (Winter-Wimmelbook, Spring-Wimmelbook, Summer-Wimmelbook, Autumn-Wimmelbook and Night-Wimmelbook) for their ability to engage readers of all ages in thrilling and never boring reading adventures. The series of five books reproduce the same environments in the four different seasons and on a summer night. It does not contain words apart from the title on the cover, various inscriptions or advertising posters on the wall of the pictured town, and the presentation on the back cover of some of the characters appearing in the visual story. The book is no longer available in Italy, so we used the German edition.

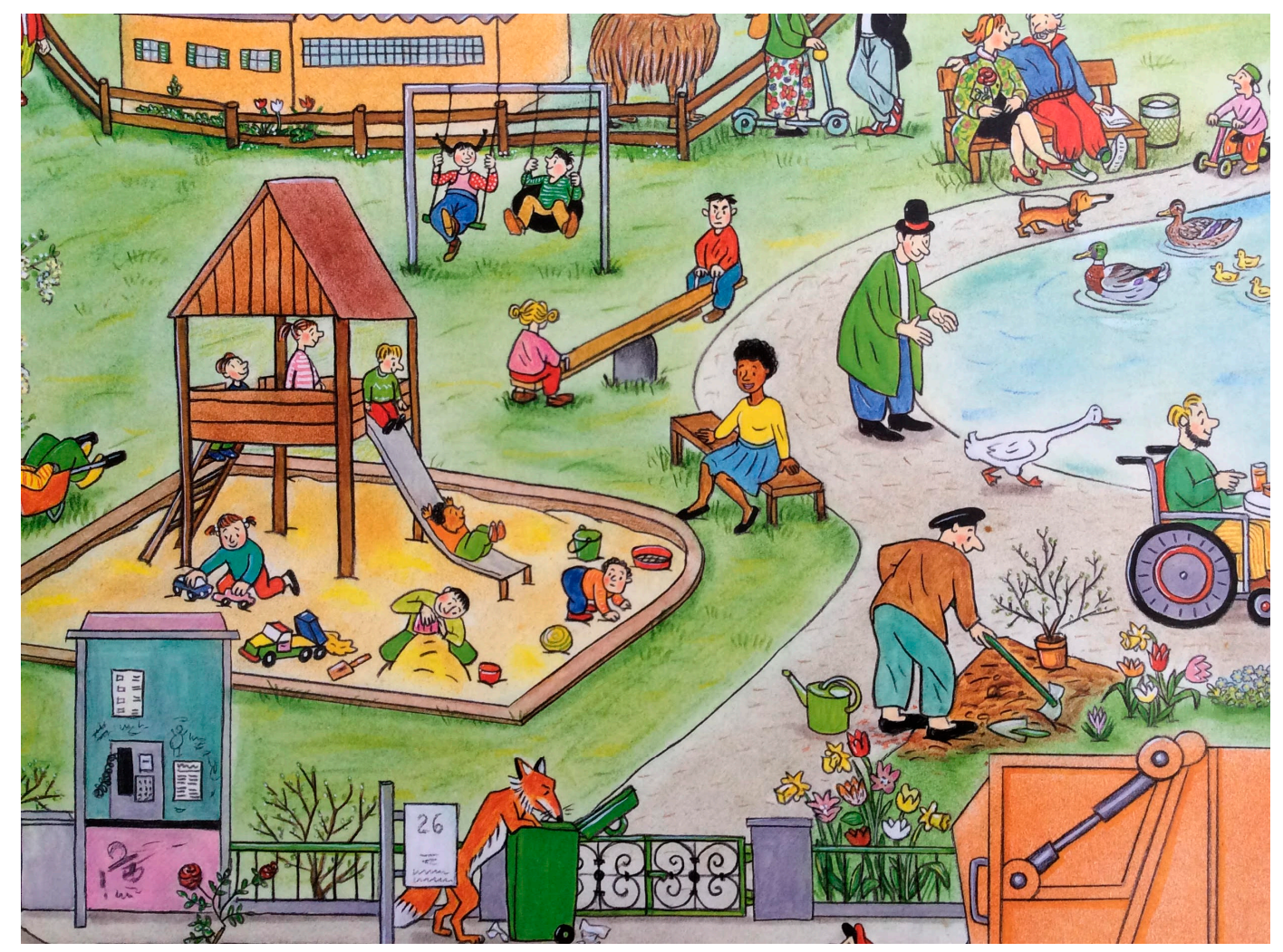

Figure 1. Detail from Spring-Wimmelbook.

The book presents a series of panels of parts of a town, Wimmlingen: a large house inhabited by different families; a countryside with a farm, a workshop and kiosk; a railway station; a neighbourhood with a kindergarten under construction and a cultural centre; the city centre with the market; a shopping centre and finally a park and a farm on the edge of the town. The book is a special type of wordless picture book. It is, as the title reveals, a "Wimmelbuch", a quite popular genre in traditional German children's literature. The German verb 'wimmeln' is translated as swarm or teem. The illustrations bring many details that literally swarm within the pages. In fact, characters, objects, animals, and details swarm within these books and readers are involved in following the illustrated characters in a narrative walk through infinite paths. According to Cornelia Rèmi [14], this is a crossover literary genre that can accompany children and in both reading and writing processes by discovering their strategies to investigate reality, to imagine and create stories, and to promote a highly active response and participation from children and adults alike.

The book's illustrator states that this type of illustration has ancient origins in primitive art and in medieval paintings, where details are often added to each other in different sizes. This is a very 
personal way of looking at the world: we all go around perceiving and focusing on certain details, which perhaps are not important unless they are important for us [24] (p. 15).

This text was chosen because readers in Wimmelbooks are always looking for new paths to follow on the traces of an item that they choose independently and according to the details that attracted their attention or stimulated their curiosity. Though addressed to children of the age group $2-5$, they involve the active participation of adult readers, who feel involved and playfully challenged by the incredibly numerous modes of observation and reading [14].

The book chosen for the primary school children is The Red Book by Barbara Lehman, first published in 2004 and printed in Italy by Il Castoro in 2007. The Red Book was the Caldecott Honor winner in 2005 and won the Anderson Award in 2008. The Red Book is a little treasure about a magical book and two children. The first child, a girl, finds a red book lying in the city on a snowy day. In the book, is a map of a tiny tropical island somewhere far away.

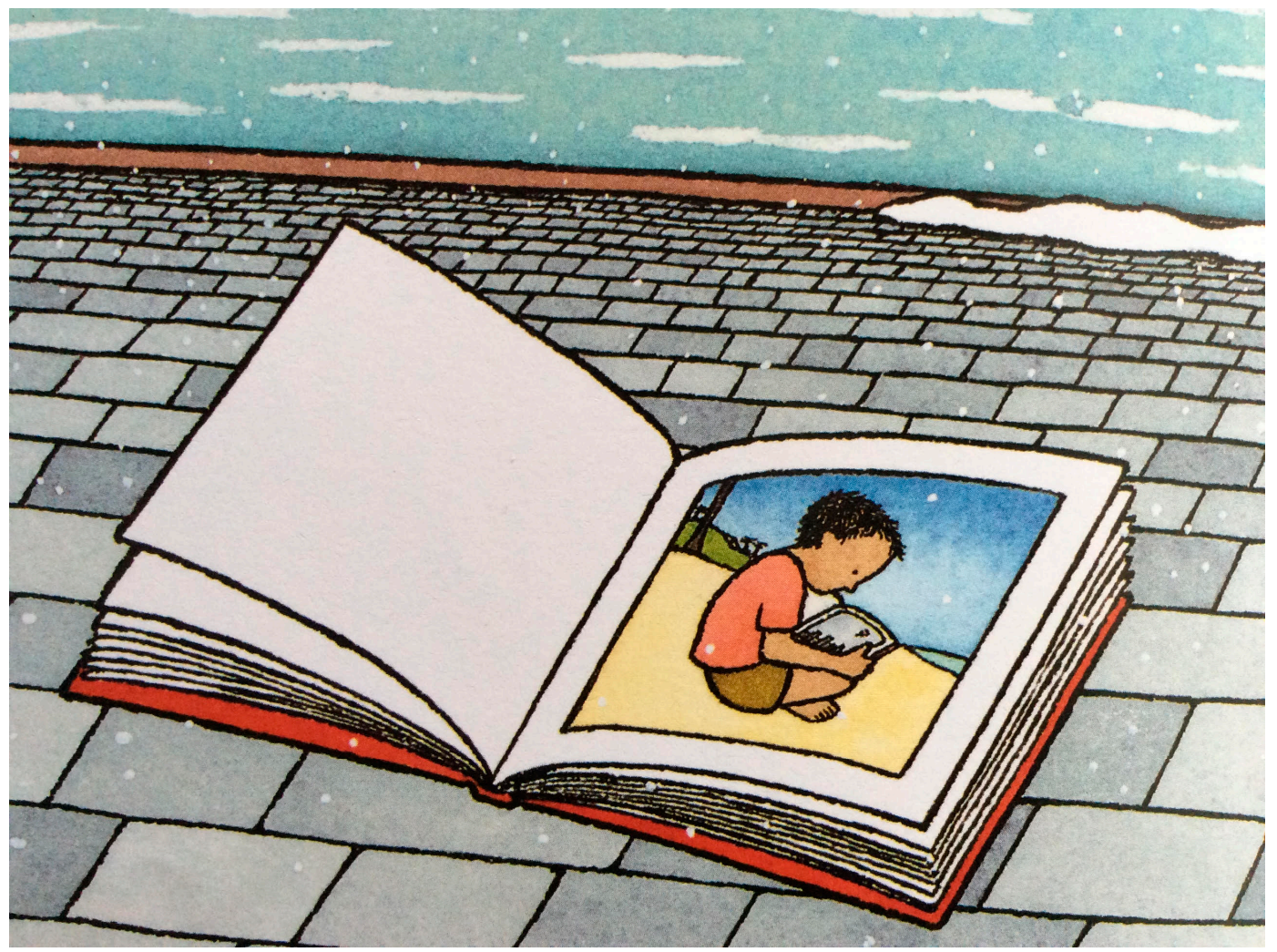

Figure 2. Detail from The Red Book.

The next series of frames zoom in to show another child finding a red book, and through the book, looking at the first child. They see each other, the girl gets an enormous bunch of balloons and flies away and finally they meet at the island. Barbara Lehman makes her book within a book, within another book using perspective, layout and borders. The effect is about looking through a camera and zooming in and out: a sort of 'mise en abyme' [25] that provokes a sensation of dizziness.

Barbara Lehman mentions that initially there was narrative text next to the illustrations, but then she realized that a purely visual narrative worked best for her story, "because of the nature of the unusual things that happen, which were easier to show than to describe" [26]. Lehman also sees in the wordless book a sort of "opposite" to what an adult reader normally does with a narrative text, that is to read and create his own mental images. Regarding visual narratives "the specific storyline is what gets created in one's mind, using the structure of the visuals, and so this is the part that will have the individual slant. I quickly came to really enjoy the variations among different children, and the additional possibility that the same child is also free to vary the story over time however it may strike them on different days or as they age" [26]. 
The Red Book offers many different possibilities of use within a school; but it has been selected especially for its richness of interpretation and for opportunities of creative thinking, as well as for the capability to capture the interest of an adult reader too.

The picture books aim to engage families in the adventure of visual reading and in the pleasure of shared and co-built reading. Participation in the project of visual reading breaks the "capsule" when school teaching practices are often locked up. Parents are not sufficiently informed about, or even completely unaware of, certain educational practices, and get the feeling that these practices lead to inert knowledge, far from the real world, the needs of children and the demands of society.

The books were taken home by single children to be read together with their parents in the task of shared reading. The children to whom the project was proposed had already used other wordless picture books with their teachers, but did not yet know this book.

The picture's meaning-making process and the reading and re-reading of the book are documented and analysed through qualitative research interviews [27], performed the next day at school. The interviews were largely collected by students of the Free University of Bolzano-Bozen (Faculty of Education). Children and parents have experienced how to read images, how to talk about images, or how to tell stories that come from images. The children took the book home from school, which freed them from formal educational connotations, and experienced a shared reading with a parent in a rather anomalous home assignment.

Recurrent themes, ideas and beliefs were identified by paying attention to the content of the data. Data from the interviews was reduced by generating categories and coding. This categorization served to organize the data and allowed us to look more closely at meaning making processes and at the value of experience.

\section{Results}

Although the collected data are not sufficient to be considered a statistically relevant outcome, the results are consistent, particularly since we collected a lot of personal and spontaneous observations about the perceived intensity of the relationship and about the process of shared reading.

The research conducted within different contexts and with different reference groups has allowed us to gather, through interviews and observations, data that confirm the effectiveness of shared reading in the co-construction of meaning and language. It also suggests interesting reflections about the contribution that the shared reading of a visual narrative provides regarding the relationship between child and adult, and the perceptions of the reading task that de-schools and becomes a play of sharing and interpretative complicity. It also demonstrates the experience of a trusted relationship and reciprocity, the expansion of contexts and educational responsibility.

From the data analysis, we can identify three macro categories or themes that relate to collaboration in the process of building meaning, to the emotional relationship and the value attributed to the project.

1. Intense parent-child interaction and collaboration:

- the process of reading and viewing is dialogical;

- the construction of language and meaning is active and participatory.

Observing and nominating figures together promotes thinking aloud and co-builds meaning and negotiating. Images support, develop, and enrich the narration; but above all they involve and include in the search for new clues or new confirmations of what has been hypothesized. "We invented the story and then checked on the next page if it was fine" (Marco, Wimmelbook); "We did not talk a lot, it was a story to tell in the head: in the end, we only discussed if the kids of the story met and we checked by the clothes if it was right".

The shared visual reading task offers children experiences of cognitive success that they can share with their parents. Children often find details that parents have missed and develop ideas that parents would not have. The child feels that he or she is the author of the text. As R. S. Berner, the author of the Wimmelbook affirms, soon after the initial low-level criticism, the image of his book 
was recognized as a highly narrative dimension. The children immediately discovered the most memorable stories and always explained them to adults [16].

The silent dialogue between adults and children is defined as extremely intimate and dense: "More than telling, talking, describing what we saw, we were astonished in silence, we felt well lying on the floor and the book was a bit a cosy nest" (Marie, mother, Wimmelbook); "We did not realize that much time had passed; We were so taken and concentrating that we did not do the shopping" (Luisa, Wimmelbook). Child and parent truly become the story's authors and are able to implement all possible strategies to speak, animate, and vivify the illustrations. The wordless picture books allowed and enhanced mistakes, inaccuracies, rotation adjustments in reading, and in the interpretation of iconotext, by creating experiences of situations in different ways and different perceptions of interpretation: children with their freedom, and parents with their need to find messages and meanings: "My son has seen much more than me, he has always helped me to identify the characters I lost or did not recognize on the next page" (Mirco, father, Wimmelbook); "I did not understand the story: my daughter recognised that the children were seen through the book and that the little girl then went to the other boy on the island" (Timo, father, The Red Book).

2. Intense emotional relationship

- shared reading as an emotional experience;

- shared reading as a care experience.

Reading seems to have created, almost unanimously, a time and space of a very intense relationship. The relationship intensifies because it is based on common visual and narrative experiences that create spaces for sharing emotions, the aesthetic perception of images and the positive interaction between child and parent that supports the growth of children [28]. Reading creates a lot of empathy and awareness of the interlocutor: the educational relationship reveals a caring relationship [29]. The parents discover the potential of their children and proudly and marvellously admire the successes of the children; the children feel good, they feel a sense of well-being and satisfaction - "It was an easy task, but mom was wrong and I corrected her because I understood the story straightaway" (Evelyn, 9 years, The Red Book); “We've been in a suspended space of wonder and astonishment for such a long time. It's been our comfort zone of the day. Less stressful than a game, more intimate and more capable of bringing us together" (Caterina, mother, Wimmelbook).

"Finally, a book that a grown-up person likes too: it was wonderful to do this task together, it was neither tiring nor boring" (Paul, father, The Red Book).

3. Educational and relational significance of the project:

- $\quad$ significance and accessibility of the task;

- value of the parents' and children's competences;

- promotion of the family role;

- perception as a successful experience, because it attributes to the child and parent the role of author of the narration.

The majority of parents spontaneously expressed their desire to repeat the experience. They emphasized the motivation value of the wordless picture books, and marvelled at the fascination and evocative power of the images, which move the perception of reading to form dimensions that go beyond the mere instructive value of reading home assignments. "Finally, a book that you should not read to summarize" (Carolina, 7 years, The Red Book). "A book that you can't stop browsing, watching and contemplating, that makes you want other books like this" (Anita, mother, Wimmelbook).

The shared reading experience has been perceived as capable of contributing to establishing a relationship of learning between parents and children. The wordless book allows children and parents to become protagonists of the act of reading because it emphasizes the ability and the potential for interpretation, makes them protagonists of their learning and as competent meaning-makers, while enhancing their creativity, giving each one the opportunity to express 
themselves regardless of the language they speak. "I was able to tell the story in my language, in the language that I am comfortable with" (Tanja, mother, Wimmelbook). The shared reading of a wordless book grants ample space to the spoken language (formulation and reformulation) and promotes family language skills, as well as the communicative relationship and negotiation of meaning.

Parents perceive text reading as communication, not just mere expression. The value of experience is in the communicative relationship between parent and child and not in the expression of the message. In fact, it seems that all this expresses another idea of the school reading task, that of a wider and more intense experience. The quality of the book for an inexperienced reader is not the quality of the text, of the illustration, of the interconnection between text and image. Parents feel to possess the instructions for reading and understanding the visual book, and this perception generates awareness of itself and gives access to a narrative of visual beauty. The school, through the visual narrative, seems to have found an excellent way to involve parents in the educational paths, proving capable of giving creative stimuli outside of itself, therefore sharing common interests with the families. The school encourages participation and collaboration to create a learning pact felt as sharing childcare and promoting everyone's skills. "This project makes me feel involved in school activity; you feel in a school community where you also have a role as a parent that you can play independently of your ability" (Petra, mother, Wimmelbook).

\section{Conclusions}

In this research project, wordless picture books have been observed as transmitters, such as aggregating and linking nodes that collaborate in building transversal experiences.

In the designed contexts, the use of wordless books with a crossover vocation has allowed us to rethink the spaces and modes of reading that involve families and children in the processes of reflection, comprehension and cognitive tension by bridging the gap between school and family. It builds a setting for the co-construction of competences, as well as for reading education based on images that will accompany the family lifelong, making the reading experience an experience of discovery-learning and a caring relationship. Finally, at the school level, new links and new knots can be observed in the network of collaboration and sharing with the family. These are not just educational spaces for visual reading outside of the school, but also, and above all, mean to anchor the school outside of the school. School tends to become an open and interactive system that promotes the dimensions of discovery, application and pleasure by expanding the object of learning, and at the same time transforming the very activity of learning.

The school needs to share experiences with families that form the first node of the educating community network. Here, the demand emerges to re-establish the density of external relationship with the families by negotiating the achievement of competences and making processes, projects and outcomes transparent and understandable. The challenge of visual reading competencies is precisely in the valorisation of the educational community, where, as Dewey [30] emphasizes, educational systems are a community of life, open to true knowledge and to the world, where education resumes its etymological value and really means "lead out", accompanying authentic contexts of learning through meaningful tools and tasks, promoting relationships of care and co-education.

Conflicts of Interest: "The authors declare no conflict of interest."

\section{References}

1. Calvino, I. Six memos for the Next Millennium; Harvard University Press: Cambridge, MA, USA, 1988; ISBN 978-0674810402.

2. Engeström, Y. 'Non scholae sed vitae discimus': Toward Overcoming the Encapsulation of School Learning. Learn. Instr. 1991, 1, 243-259.

3. Arizpe, E.; Styles, M. Children Reading Pictures: Interpreting Visual Texts, 2nd ed.; Routledge: Oxon, UK, 2016; ISBN 978-1138014077. 
4. Arizpe, E. Meaning-making from wordless (or nearly wordless) picturebooks: What educational research expects and what readers have to say. Camb. J. Educ. 2013, 43, 163-176.

5. Nikolajeva, M.; Scott, C. How pictures Work, 3rd ed.; Garland: New York, NY, USA; London, UK, 2006; ISBN 978-1138126930.

6. Beckett, S.L. Wordless Picturebooks. In Crossover Picturebooks: A Genre for All Ages; Beckett, S.L., Ed.; Routledge: London, UK; New York, NY, USA, 2012; pp. 81-125, ISBN 978-0-415-87230-0.

7. Campagnaro, M.; Dallari, M. Incanto e Racconto nel Labirinto Delle Figure; Erickson: Trento, Italy, 2013; ISBN 9788859001621.

8. Mayring, P. Einführung in Die Qualitative Sozialforschung; Verlagsgruppe Beltz: Weinheim, Germany, 2002; ISBN 978-3407252524.

9. Richey, V.H.; Tuten-Puckett, K.E. Wordless/Almost Wordless Picture Books: A Guide; Libraries Unlimited: Englewood, CO, USA, 1992; ISBN 978-0872878785.

10. Bosch, E. ¿Cuántas Palabras Puede Tener un Álbum sin Palabras? Revista OCNOS 2012, n 8; Universidad de Castilla-La Mancha: Castilla-La Mancha, Spain, 2012; pp. 75-88, ISSN 1885-446X.

11. Serafini, F. Exploring wordless picture books. Read. Teach. 2014, 68, 24-26, doi:10.1002/trtr.1294.

12. Terrusi, M. Silent book per tutti i lettori in ascolto. Andersen 2014, 309, 14.

13. Terrusi, M. Meraviglie Mute. Silent Book e Letteratura per l'Infanzia, 2017; Carocci: Rome, Italy, 2017; ISBN 9788843086122.

14. Rémi, C. Reading as Playing: The Cognitive Challenge of the Wimmelbook. In Emergent Literacy: Children's Books from 0 to 3; Kümmerling-Meibauer, E., Ed.; Benjamins: Amsterdam, The Netherlands, 2011; pp. 115139, ISBN 978-90-272-1808-7.

15. Tan, S. The accidental graphic novelist. Bookbird A J. Int. Child.'s Lit. 2011, 49, 1-9.

16. Gradwohl, N. Bilder Machen eine Zusätzliche Welt zum Text auf. 2016. Available online: https://www.srf.ch/kultur/literatur/bilder-machen-eine-zusaetzliche-welt-zum-text-auf (accessed on 10 September 2017).

17. Bader, B. American Picturebooks from Noah's Ark to the Beast within; Macmillan Pub Co.: New York, NY, USA, 1976; ISBN 978-0027080803.

18. Pontecorvo, C.; Ajello, A.M.; Zucchermaglio, C. I Contesti Sociali dell'Apprendimento; LED: Milano, Italy, 1995; ISBN 8879160575.

19. Lave, J.; Wenger, E. Situated Learning: Legitimate Peripheral Participation; Cambridge University Press: Cambridge, UK, 1991; ISBN 978-0521423748.

20. Engeström, Y. Learning by Expanding, 2nd ed.; Cambridge University Press: Cambridge, UK, 2014; ISBN 978-1107074422.

21. Ajello, A.M.; Ghione, V. La scuola dell'autonomia come sistema complesso: Un modello di analisi. In Psicologia e Scuola. Una Prospettiva Socioculturale; Ajello, A.M., Ghione, V., Belardi, C., Eds.; Valore Italiano $^{\mathrm{TM}}$-Infantiae.Org ${ }^{\mathrm{TM}}$ : Rome, Italy, 2015; ISBN 978-88-89529-10-2.

22. Berner, R.S. Frühlings-Wimmelbuch; Gerstenberg Verlag: Hildesheim, Germany, 2004; ISBN 978-3-8369-5057-2.

23. Lehman, B. The Red Book; Houghton Mifflin: New York, NY, USA, 2004; ISBN 978-0618428588.

24. Berner, R.S. Ich will keine Konflikte auftürmen. Buch Maus 2008, 4, 14-17.

25. Berta, L. Oltre la mise en abyme: Teoria della Metatestualità in Letteratura e Filosofia; FrancoAngeli: Milan, Italy, 2006; ISBN 9788846474049.

26. Schafer, C. Wordless Wednesday. The Red Book E Interview with Barbara Lehman. 2016. Available online: http://www.threebooksanight.com/book-reviews/the-red-book/ (accessed on 10 September 2017).

27. King, N.; Horrocks, C. Interviews in Qualitative Research; Sage: Los Angeles, CA, USA, 2010; ISBN 978-1412912570.

28. Levorato, M.C. Le Emozioni Della Lettura; Il mulino: Bologna, Italy, 2000; ISBN 978-8815073754.

29. Noddings, N. The Challenge to Care in Schools, 2nd ed.; Teachers College Press: New York, NY, USA, 2005; ISBN 978-0807746097.

30. Dewey, J. Democracy and Education; Dover: Mineola: New York, NY, USA, 1916/2004; ISBN 978-1449983673. 